\title{
Fluconazole - a case report on fixed drug eruption
}

\author{
Magna Correia ${ }^{1 *}$, Magna Correia ${ }^{2}$, João Freitas², Rita Vieira², Filipe Perneta ${ }^{2}$, Luz Brazão ${ }^{2}$ \\ From 6th Drug Hypersensitivity Meeting (DHM 6) \\ Bern, Switzerland. 9-12 April 2014
}

\section{Background}

Adverse reactions to drugs, Fixed Erythema (FE), correspond to $16-21 \%$ of all skin eruptions. This disease results in the development of one or more erythematous annular or oval, plaques as a result of systemic exposure to a drug. On reexposure relapse occurs in the same place, although new lesions may arise simultaneously in other areas. Any drug can cause FE. The physiopathology involves an allergic reaction (vasculitis).

\section{Methods and material}

After theoretical revision and the consultation of the clinical file, the authors present a clinical case of fixed drug eruption to Fluconazole, pointing out the anamnesis, the examination and further complementary exams of diagnosis.

\section{Case study}

Female patient of 43 years, with a past history of recurrent vaginal candidiasis, treated every time with oral Fluconazole that attended our emergency department with well demarcated erythematous plaque located on the right side of the upper lip. The patient referred that the beginning of the injuries occurred about 12 hours after taking $150 \mathrm{mg}$ of fluconazole and mentioned no pain our itchy sensation. Our initial assessment was simultaneous vaginal candidiasis and herpes simplex. As so Valaciclovir was prescribed and the patient was discharged. However after the 4th day of treatment a new lesion similar to the first appeared on the dorsal part of her hand. On this new signal, the patient was diagnosed with fixed pigmented erythema to fluconazole. She stopped Valaciclovir and Fluconazole and started a topical medium power corticosteroid and a systemic antihistamine.

IInternal Medicine Department - Central Hospital of Funchal - Madeira Portugal, Portugal

Full list of author information is available at the end of the article

\section{Conclusion}

FE has a spontaneous recovery and no complications with drug withdrawal. The use of antihistamines and topical corticosteroids relieve symptoms associated with the disease.

\section{Authors' details \\ ${ }^{1}$ Internal Medicine Department - Central Hospital of Funchal - Madeira, Portugal, Portugal. ${ }^{2}$ SESARAM, Internal Medicine, Portugal.}

Published: 18 July 2014

doi:10.1186/2045-7022-4-S3-P72

Cite this article as: Correia et al:: Fluconazole - a case report on fixed drug eruption. Clinical and Translational Allergy 2014 4(Suppl 3):P72.
Submit your next manuscript to BioMed Central and take full advantage of:

- Convenient online submission

- Thorough peer review

- No space constraints or color figure charges

- Immediate publication on acceptance

- Inclusion in PubMed, CAS, Scopus and Google Scholar

- Research which is freely available for redistribution

Submit your manuscript at www.biomedcentral.com/submit
() Biomed Central 